\title{
A Study of Operational Troubles Due to Ship Motions in the Seto Inland Sea
}

\author{
Kenji SASA ${ }^{*}$ and Shinji MIZUI*
}

\begin{abstract}
It is important to maintain the regularity and the safety of maritime transportation. For example, many people who live around the Seto Inland Sea have to depend on ferry services. Although many casualties have been reported there, ship motions due to waves have not been studied previously. It is believed that oceanographic conditions are calm in the Seto Inland Sea. In this study, operational troubles of local ferries are researched in detail. First, the interview research was carried out regarding the cancellation of navigation. It is known that the local ferry service has been canceled several times in the winter season to prevent the damage of cargos due to ship motions. Second, the field observations of ship motions were carried out in this winter season. The roll motion becomes remarkable under a west wind of $9-15 \mathrm{~m} / \mathrm{s}$. Observed results can verify that waves are generated under strong winds or currents, which may cause such ship motions. More research, such as the wave observation, will be necessary in the future.
\end{abstract}

Key words: Ship Motions, Seto Inland Sea, Waves, Cancel of Ship Operation, Winds, Currents

\section{Introduction}

There is a lot of vessel traffic in the Seto Inland Sea because of its geographical conditions. Although many bridges have been built across the Seto Inland Sea, there are still many people who have to depend on the marine traffic service. According to the marine accident reports, ${ }^{(1)}$ the number of casualties is not negligible in this area. However, most of the casualties are attributed to human error because it is generally believed that the oceanographic conditions are calm there. On the other hand, we think that the oceanographic conditions are not necessarily calm in the Seto Inland Sea. This point has not been discussed because oceanographic conditions have not been observed or studied very much. Firstly, the interview research about ship operations was carried out with ferry companies in the Seto Inland Sea. Some problems exist with large ship motions due to strong winds in the winter season. They sometimes cause the cancellation of navigation. We carried out the field observation of ship motions of the local ferry at spring tides in the winter season. Those data are analyzed to determine the properties of ship motions in detail when the ferry enters harbors or navigates offshore. Furthermore, some relationships are found in the observed data. Finally, the overall safety of ship operation is considered, and the necessity of oceanographic observation is proposed.

\section{Difficulties of Operation in the Winter Season}

The fact that the ship operation becomes difficult in the winter season can be obvious, even in the Seto Inland Sea. First, the results of the interview research are summarized. Then weather conditions in these situations are examined.

\subsection{Interview Research on Ship Operations}

The interview was carried out with employees of the local ferry company. The company provides the regular service between Takehara Port and Namikata Port, which are located in the Geiyo district in the Seto Inland Sea. Figure 1 shows the navigation route of the ferry. The navigation usually takes 1 hour and 10 minutes. There are many islands in this area, so strong currents and large tides may be generated.

* Member Hiroshima National College of Maritime Technology sasa@hiroshima-cmt.ac.jp 
Especially, the navigation rules are very complicated at the Kurushima Strait, which is located near the Namikata Port. Table 1 shows the results of interviews about the difficulty of operation.

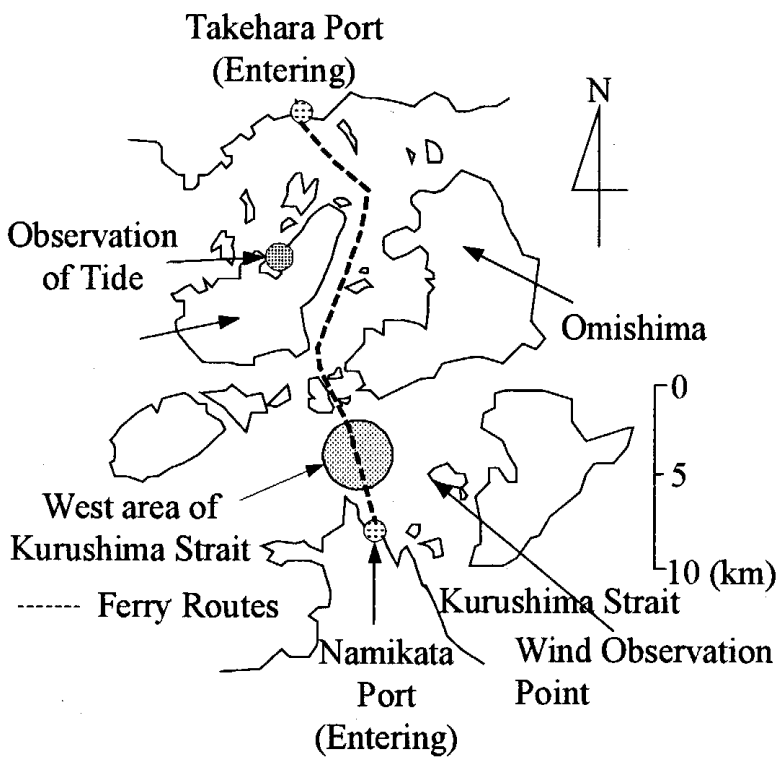

Fig. 1 Navigation route of the ferry

Table 1 Description of interview research

\begin{tabular}{|l|l|l|}
\hline Sea area & Time & Operational difficulty \\
$\begin{array}{l}\text { West area } \\
\text { of } \\
\text { Kurushima } \\
\text { Strait }\end{array}$ & $\begin{array}{l}\text { Winter } \\
\text { season }\end{array}$ & $\begin{array}{l}\text { Ship motions (Especially } \\
\text { roll motion) become } \\
\text { larger when seasonal } \\
\text { winds become strong. } \\
\text { Chopping waves are } \\
\text { generated there. }\end{array}$ \\
\hline $\begin{array}{l}\text { Namikata } \\
\text { Port }\end{array}$ & $\begin{array}{l}\text { Spring entry into port used to } \\
\text { be difficult due to the } \\
\text { influence of strong } \\
\text { currents. However, this } \\
\text { point has improved with } \\
\text { the installation of } \\
\text { thrusters. }\end{array}$ \\
\hline
\end{tabular}

As shown in the table, ship operators comment that the navigation becomes difficult near Kurushima Strait when strong winds from the west and ebb currents from Kurushima Strait make chopping waves. Figure 2 shows an illustration of this phenomenon.

These chopping waves cause large ship motions, and the collapse of cargos loaded on tracks may happen in some cases. The ferry service has been canceled under strong winds in the winter season from the viewpoint of the safety of cargos. The trouble of ship operation due to waves is a new discovery in an area where oceanographic conditions are thought to be very calm.

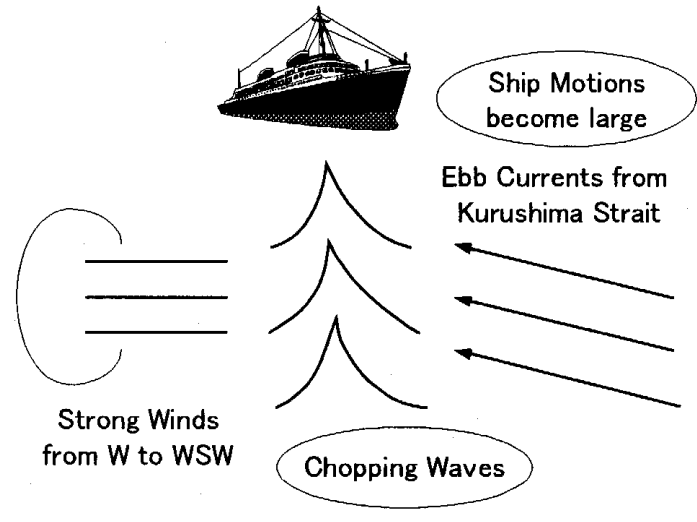

Fig. 2 Chopping waves near Kurushima Strait

\subsection{Distribution of Atmospheric Pressure}

Table 2 shows the date and the conditions under which the company canceled its services.

Table 2 Cancellation of navigation in winter

\begin{tabular}{|l|l|l|}
\hline Year & Date & Situation of cancellation \\
\hline 2000 & Dec. 23 & $\begin{array}{l}\text { Wind: WSW } 17 \mathrm{~m} / \mathrm{s} \\
\text { The loading of trucks was } \\
\text { canceled. }\end{array}$ \\
\hline 2000 & Dec. 25 & Wind: W 20m/s \\
\hline 2001 & Feb. 3 & All navigations were canceled. \\
\hline 2001 & Feb. 16 & $\begin{array}{l}\text { Wind: West } 13 \mathrm{~m} / \mathrm{s} \\
\text { Weather conditions were } \\
\text { similar to typhoons. }\end{array}$ \\
\hline 2001 & March 5 & $\begin{array}{l}\text { Wind: WSW } 16 \mathrm{~m} / \mathrm{s} \\
\text { The loading of trucks was } \\
\text { canceled. }\end{array}$ \\
\hline 2001 & March 8 & $\begin{array}{l}\text { Wind: WSW 13m/s } \\
\text { The loading of trucks which } \\
\text { used papers or timbers was } \\
\text { canceled. }\end{array}$ \\
\hline
\end{tabular}

It shows that there are 6 days when navigation was canceled in the winter season. This situation does not seem to be negligible for a ferry operation. It is reported that strong winds blow from West to WSW directions. Figures 3-4 show meteorological charts on December 24, 2000, and March 5, 2001.

They are typical distributions of atmospheric patterns of western highs and eastern lows. Many casualties have occurred in the open seas, such as the Pacific Ocean or the Sea of Japan, under these conditions. ${ }^{(2)}$ High atmospheric pressures are located in the East China Sea, so the constant pressure line around 1010-1020hPa stays north and south of the Seto Inland Sea. This can explain the 
phenomenon of strong winds from West to WSW. However, there are no systems for observing waves or currents there. The characteristics of chopping waves are still unknown.

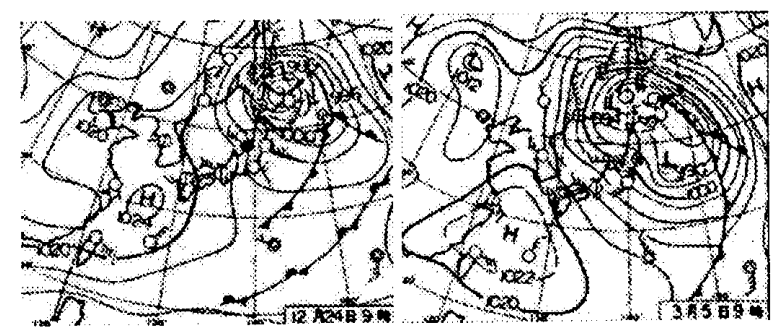

Fig. 3 Weather chart on Fig. 4 Weather chart on

December 24, 2000 March 5, 2001

\section{Observation of Ship Motions}

In this study, ship motions are observed during navigation and entry into the harbor. Each condition of observation is shown as follows.

\subsection{Conditions of Ship and Sea Area}

Figure 5 shows the picture of the ferry which we used for the observation.

The dimensions of the ferry are as follows: $L_{P P}$ is $55 \mathrm{~m}$, and breadth is $14 \mathrm{~m}$. Other parameters are a bit varied under different loading conditions. Draft is $2.45 \mathrm{~m}, G M$ is $2.66 \mathrm{~m}, K G$ is $4.53 \mathrm{~m}$, and displacement was 1,009 tons at the time of the observation on December 26. The ferry has two propellers and two rudders, and the right turning circle is $50 \mathrm{~m}$ larger than the left one. It is necessary for ship operators to consider this point at the entering and departing harbors.

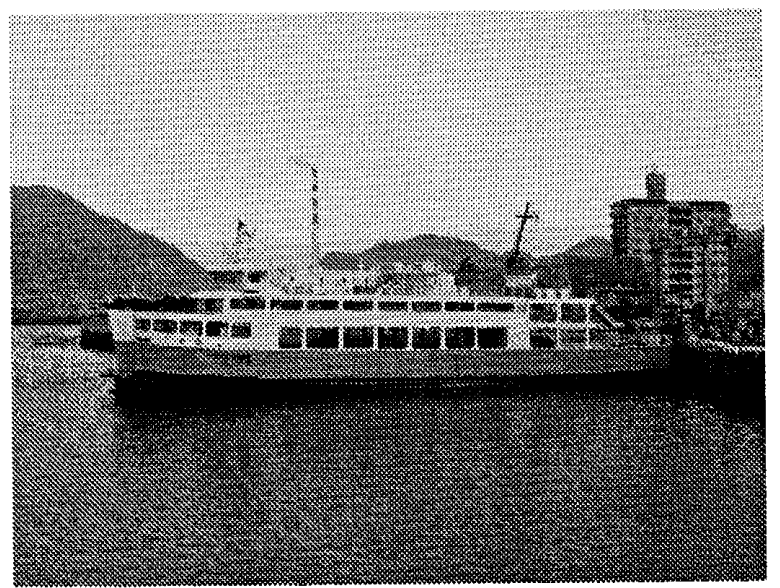

Fig. 5 View of the ferry
Ship motions were observed by an observation system which consists of a GPS, an optical fiber gyro, and a gyro compass. It can observe the position, the speed, the motions of 6 modes, etc. with high accuracy. ${ }^{(3)}$ In this study, the whole unit was installed inside the ferry during the winter season.

\subsection{Weather Conditions at Observations}

The observation was carried out several times at spring tides in the winter season. Table 3 shows the date and wind conditions of the observation. The Japan Coast Guard observes wind directions and wind speeds on a small island near Kurushima Strait as shown in Fig. $1 .^{(4)}$ In this study, those wind data are used to consider the ship motions occurring offshore Kurushima Strait. Figures 5-6 show the weather charts on January 11 and on April 22.

Table 3 Date and wind conditions during observation

\begin{tabular}{|l|l|l|}
\hline Date & Time & Wind Condition \\
\hline December 26 & $15: 00-18: 00$ & West-NW, 5-8m/s \\
\hline January 11 & $6: 00-21: 00$ & West, 10-16m/s \\
\hline January 12 & $6: 00-21: 00$ & $\begin{array}{l}\text { West-WNW, } \\
6-11 \mathrm{~m} / \mathrm{s}\end{array}$ \\
\hline January 22 & $6: 00-12: 00$ & Calm, 1-2m/s \\
\hline February 10 & $12: 00-18: 00$ & NW-NNW, 5-10m/s \\
\hline March 11 & $5: 00-20: 00$ & $\begin{array}{l}\text { West-WSW, } \\
5-10 \mathrm{~m} / \mathrm{s}\end{array}$ \\
\hline April 22 & $13: 00-19: 00$ & $\begin{array}{l}\text { West-WSW, } \\
8-11 \mathrm{~m} / \mathrm{s}\end{array}$ \\
\hline
\end{tabular}

In Fig. 5, atmospheric depressions develop at sea in northeast of Japan. They seem to be similar to those in Fig. 3. The constant pressure line of $1020 \mathrm{hPa}$ is located in the observation area. It probably created the strong wind from West to WNW.

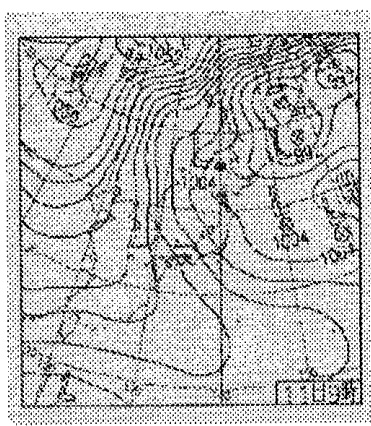

Fig. 5 Weather chart on January 11, 2005

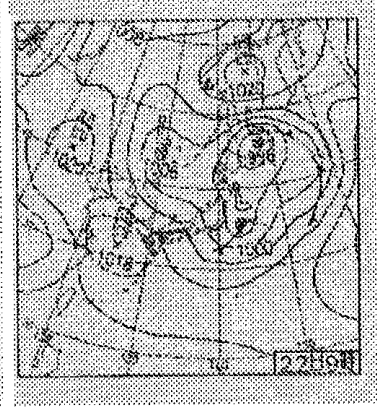

Fig. 6 Weather chart on April 22, 2005
In Fig. 6, three atmospheric depressions exist 
around the Japanese island. Parallel constant pressure lines are located in the western part of Japan. This looks like the storm pattern in the spring season.

\subsection{Observation of Tide Conditions}

It is also necessary to know tide changes in the observation area. The system for observing tide levels is constructed on the OK island as shown in Fig. 1. It continuously records the tide level, the air pressure, the water temperature, etc.

\section{Analysis of Ship Motions in Each Situation}

Observed data of ship motions were analyzed in the following situations.

\subsection{Ship Motions at Takehara Port and Namikata Port}

When the ferry enters the Takehara Port, it turns counterclockwise, as shown in Fig. 7.

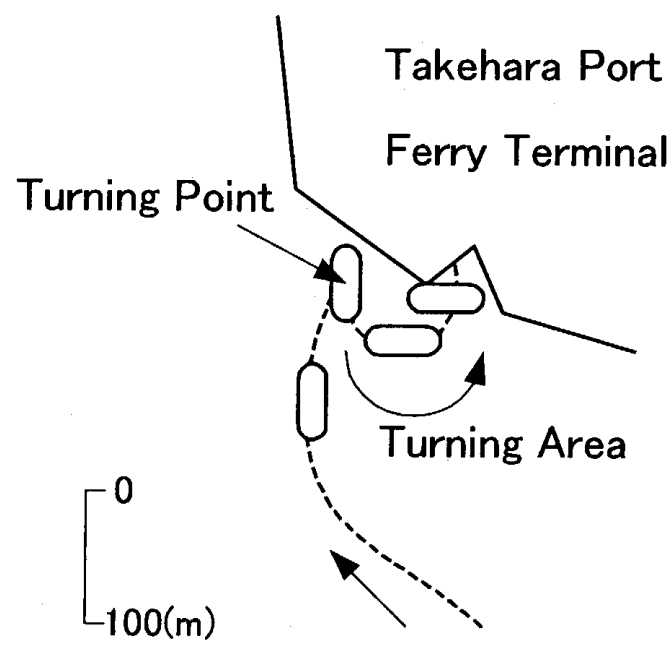

Fig. 7 Manoeuvering pattern at Takehara Port

The turning situation seems to be difficult when water depth is decreased by low tides. ${ }^{(5)}$ Figure 8 shows the observed ship trails at Takehara Port.

There are several cases in which the turning radius is $10-20 \mathrm{~m}$ larger in the figure. The relation analysis among turning radii, tide levels, and wind speeds was carried out to know the influence of tides on this result. Figure 9 shows observed ship trails of the ferry departing from the Namikata Port.

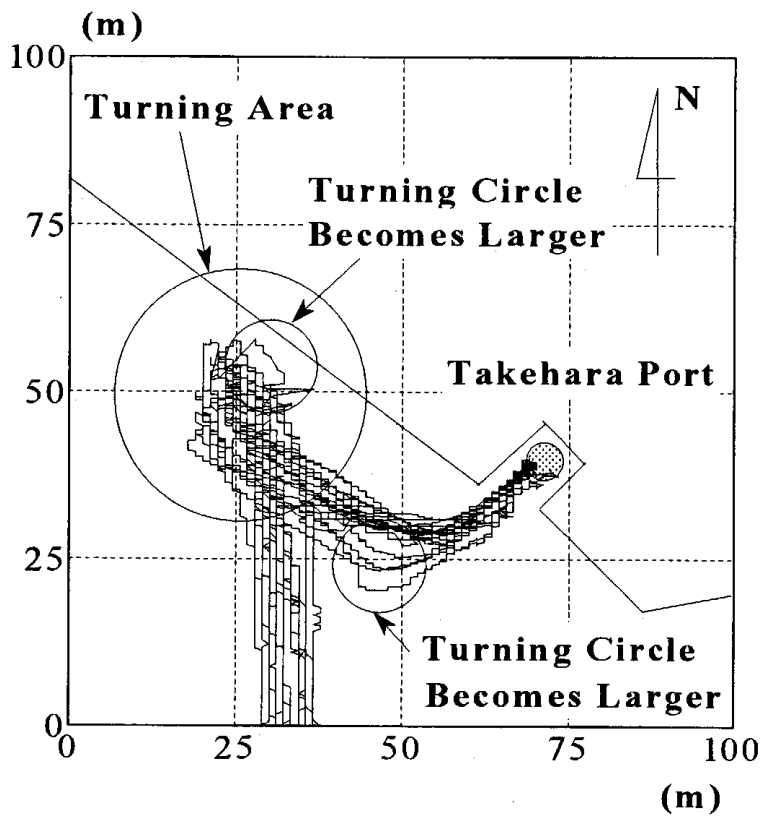

Fig. 8 Observed ship trails at Takehara Port

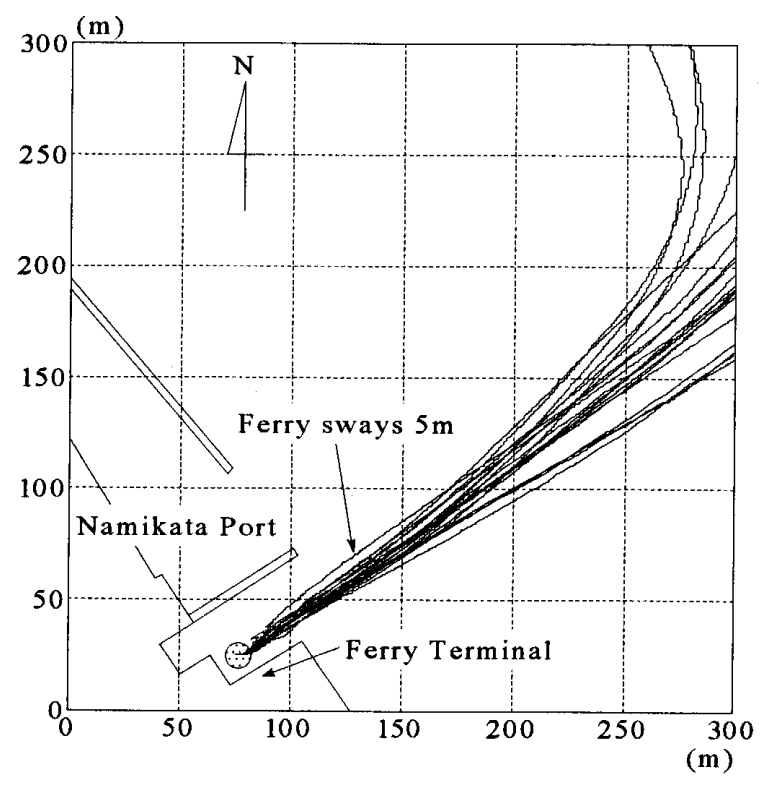

Fig. 9 Observed ship trails at Namikata Port

According to interviews, ferries used to have difficulty entering the Namikata Port at spring tides. However, there is only one case of the ferry swaying at berthing. Thrusters probably make the ferries' smooth maneouvring possible. Thus, this situation does not cause any serious problems with the influence of strong currents at spring tides.

\subsection{Ship Motions near Kurushima Strait}

As shown in chapter 2, ship motions sometimes make the ship operation very difficult in the winter season. In this study, ship motions can be observed 
when the wind speed exceeds $10 \mathrm{~m} / \mathrm{s}$. Figure 10 shows the time history of roll and pitch motions from 14:46 to $15: 00$ on April 22.
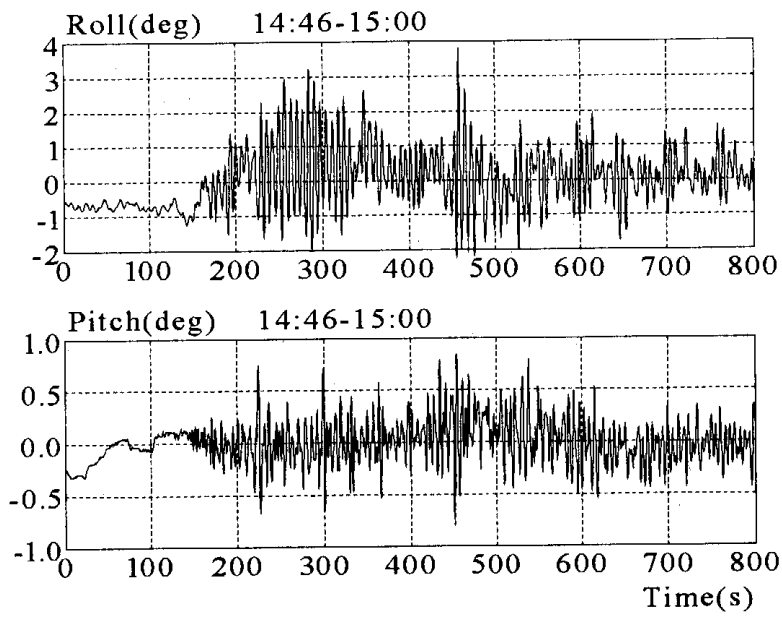

Fig. 10 Observed ship motions near Kurushima Strait (April 22, 14:46-15:00)

The roll motion in particular reaches almost 3 degrees at the maximum in this case. The pitch motion also becomes $0.5-1$ degree. The spectrum analysis was carried out to analyze the frequency in detail. Figure 11 shows the spectrum of observed roll motions on April 22.

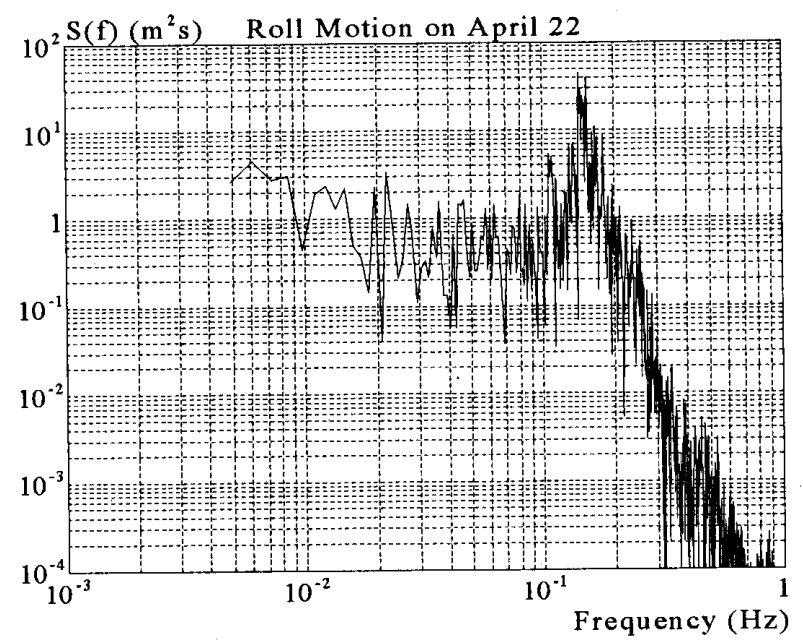

Fig. 11 Spectrum of roll motion (April 22, 14:46-15:00)

The natural period of roll motion can be estimated as follows:

$$
T_{R}=\frac{0.8 B}{\sqrt{G M}}=\frac{0.8 \times 14}{\sqrt{2.66}}=6.86(\mathrm{~s})
$$

where $T_{R}$ is the natural period of roll motion, $B$ is the breadth, and $G M$ is the metacenter height. In Fig. 11, a peak period exists around $0.15 \mathrm{~Hz}(6.7 \mathrm{~s})$, which is very close to the natural period of roll motion. External forces from a lateral direction have to be dominant because of the geometrical relation among the ferry, the winds, and the currents, as shown in Fig. 1. Observed results show that wave forces make the ferry operation very difficult, even in the Seto Inland Sea. However, waves have not been studied in this area up to now. It is necessary to observe them in the future in order to analyze chopping waves.

\section{Relation Analysis between Ship Motions and Oceanographic Conditions}

Some difficulties of ship operations can be verified by observed data. The correlation between the ship motions and the oceanographic conditions is researched here. The relation between the turning radius and the tidal level and between the turning radius and the wind speed is shown in Fig. 12. The wind speed is observed near Takehara Port by the Japan Meteorological Agency. ${ }^{(6)}$ The observed data is offered on their website.
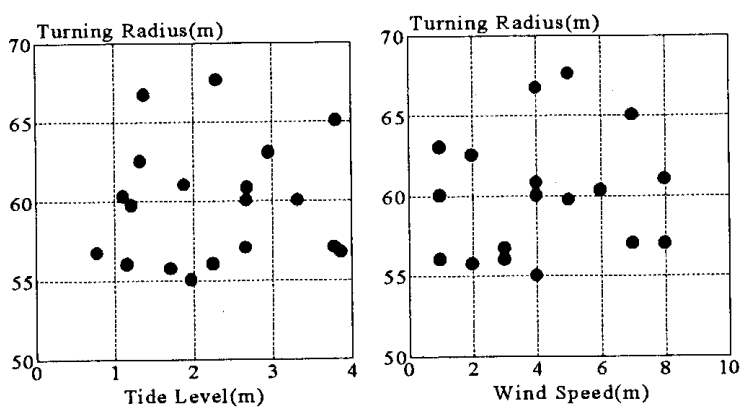

Fig. 12 Relation among turning radius, tide level, and wind speed

The turning radius varies from 55-68 meters. Although it seems to be larger as the tide level lowers, there is not an obvious correlation between the turning radius and the tide level here.

Ship motions near Kurushima Strait are considered as follows. The relation between ship motions and wind speeds is shown in Fig. 13.

Current conditions are also shown in these figures. Roll and pitch motions seem to become larger as wind speeds increase. Ship motions are at maximum values when the wind speed is $10 \mathrm{~m} / \mathrm{s}$. Theoretically, the strong winds must generate waves because pitch and roll motions are caused by wave forces. These 
figures also show that ship motions increase in both current conditions. The assumption that the ebb current and the strong wind make the chopping waves in the sea is not verified by observed results. Thus, the observation of chopping waves is necessary to examine their properties in the future.
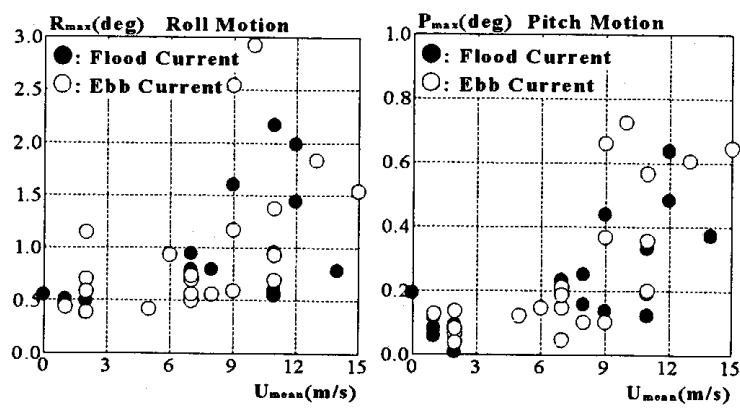

Fig. 13 Relation between ship motions and wind speeds in each current condition

\section{Conclusions and Future Subjects}

In this study, the difficulty of ship operation was researched using the local ferry in the Geiyo district in the Seto Inland Sea. The existence of waves can be found in this area, and it creates a large amplitude of ship motions. Main conclusions and future subjects are summarized as follows.

(1) According to the interview research, the operational difficulty still exists when ships navigate in the western area of Kurushima Strait at strong winds and currents although the Seto Inland Sea is known as a calm area.

(2) Ship motions were first observed at spring tides from winter to spring seasons. The turning circles for berthing at the Takehara Port became $10-20 \mathrm{~m}$ larger in some cases.

(3) The roll motions became 2-3 degrees when the wind speed was $9-16 \mathrm{~m} / \mathrm{s}$. Observed results can verify the existence of waves that cause the ferry operation so much difficulty, even in the Seto Inland Sea.

(4) The relation among the turning radius, tide level, and wind speed was investigated. It became obvious that the length of the turning circle was not influenced very much by tide changes. It seems to be more influenced by wind speeds.

(5) The relation among ship motions, wind speeds, and current directions is researched here. It is obvious that ship motions become larger as wind speeds increase. On the other hand, ship motions do not seem to be influenced by current directions.

(6) The properties of the waves in this area are still unknown, so they need to be studied in detail. A method of observing the waves needs to be established for the safety of navigation in the future.

\section{Acknowledgements}

We are grateful to Mr. Kuniaki Irikawa and ship crews of the Chushikoku shipping company who cooperated with the field observation. We want to express our appreciation to Mr. Ryosuke Saeki, a student of Hiroshima National College of Maritime Technology, for his assistance in analyzing the large amount of observation data.

\section{References}

(1) Marine Accident Inquiry Agency in Japan: http://www.mlit.go.jp/maia/05boushi/bunseki/bunse kitop.htm (2005) (in Japanese)

(2) Shiraishi, S., Kubo, M., Ueda, S. and Sakakibara, S.: "Countermeasure by Mooring System for Moored Ship Motions Under Long Period Waves", Proceedings of the 5th International Symposium on Coastal Ocean Space Utilization, pp.207-216 (1996) (3) Sasa, K., Kubo, M., Shiraishi, S. and Cho, I.: "Basic Research on Safety at Entering and Departing Harbours Subjected to Wave Induced Ship Motions", The Journal of Japan Institute of Navigation, Vol.109, pp.179-189 (2003)

(4) Kurushima Kaikyo Advisory Service Center: http://www6.kaiho.mlit.go.jp/kurushima/ (2005)

(in Japanese)

(5) Sasa, K., Mizui, S., Nagai, T. and Hibino, T: "Basic Research on Operational Troubles for Ships and Harbours Due to Abnormal Water Levels", Proceedings of the 15th International Conference of Offshore and Polar Engineering, Vol. III, pp.720-727 (2005)

(6) Japan Meteorology Agency: http://www.data. kishou.go.jp/etrn/index.html (2005) (in Japanese)

\section{Question and Answer}

Question: Kohei Hirono(Kobe University) 
Please show me your viewpoint of this study now and then about these points.

(1) Why do you select the sea area and the navigation route in this study?

(2) I think that the information support of this study seems to be effective. What do you think about this point?

\section{Answer: Shinji Mizui}

We carried out the nationwide questionnaire about ship operation against many ferry companies. This research result makes us clear the existence of operational problems due to ship motions by waves. We focus on the point that the problem occurs in the restricted sea areas such as the Seto Inland Sea. Then, the ship motions are actually observed under spring tides and strong winds in winter season. And the mechanism about the generation of chopping waves near the Kurushima Strait is still unknown. This point will be very important factor for the safety of navigation. Thus, the wave observation point should be constructed in the Geiyo district in Seto Inland Sea as stated in this study. Furthermore, we think that the construction of wave network system in the Seto Inland Sea is more effective from the viewpoint of the information support. 